\title{
Estimation of Unperturbed Chain Dimensions of Cellulose, Amylose, and Their Derivatives in Solution from Frictional Coefficient Data
}

\author{
Kenji Kamide and Yukio MiYazaKI \\ Textile Research Laboratory, Asahi Chemical Industry Co. Ltd., \\ Takatsuki, Osaka 569, Japan.
}

(Received January 7, 1978)

\begin{abstract}
An attempt was made to establish a method (method $2 \mathrm{~J}$ ) for estimating the unperturbed chain dimensions $A\left[\equiv 6^{1 / 2}\left(\left\langle S^{2}\right\rangle_{0} / M\right)^{1 / 2} .\left\langle S^{2}\right\rangle_{0}^{1 / 2}\right.$, unperturbed radius of gyration; $M$, molecular weight] of polymers from the frictional coefficient $\xi$ in the case when the polymer chains are non-Gaussian and the draining effect cannot be ignored. The following equation was derived:

$$
\xi / \eta_{0}=6^{1 / 2} K_{\mathrm{p}} K_{0}^{0.5} M^{0.5+0.5 a_{2}+a_{\mathrm{p}}}\left(1+0.0144 B K_{0}^{-1.5} M^{0.5-1.5 a_{2}}\right)
$$

where $\eta_{0}$ is the viscosity of the solvent, $B$ is a long-range interaction parameter, $K_{\mathrm{p}}$ and $a_{\mathrm{p}}$ are parameters in the equation of the molecular weight dependence of the Flory parameter $P$ as defined by $P=K_{\mathrm{p}} M^{a_{\mathrm{p}}}, K_{0}$ and $a_{2}$ are parameters in the relation: $\left\langle S^{2}\right\rangle_{0} / M=K_{0} M^{a_{2}}$. By putting $a_{2}=a_{\mathrm{p}}=0$, the above equation reduces to practically the same equation as that obtained by Cowie and Bywater (method 2I). These two methods (method 2J and 2I) were applied to literature data on cellulose, cellulose diacetate, cellulose tricarbanilate, ethylhydroxyethyl cellulose, and amylose triacetate. Method $2 \mathrm{~J}$ meets with great success in elucidating the $A$ value for these polymers. The $A$ value as determined by method 2I is only some $50 \%$ of the most reliable value.
\end{abstract}

KEY WORDS Unperturbed Chain Dimensions / Friction Coefficient /

Draining Effect / Non-Gaussian Chain / Cellulose Derivative /

Amylose Derivative /

In a previous paper $^{1}$ we have determined the most reliable short-range parameter $A\left[=6^{1 / 2}\left(\left\langle S^{2}\right\rangle_{0}\right)\right.$ $M)^{1 / 2} .\left\langle S^{2}\right\rangle_{0}^{1 / 2}$, radius of gyration at unperturbed state; $M$, molecular weight] for cellulose, amylose, and their derivatives by using thermodynamic and viscometric approaches. It has been confirmed in this paper that polymer chains are non-Gaussian and the contribution of the draining effect to hydrodynamic properties, including limiting viscosity number $[\eta]$, and sedimentation and diffusion coefficients at infinite dilution, $s_{0}$ and $D_{0}$, can never be ignored. When these effects are reasonably taken into account in the methods for estimating $A$, almost the same $A$ values are obtainable for any given polymer-solvent pair.

The frictional coefficient $\xi$ is defined by eq 1 or eq $1^{\prime}$ :

$$
\begin{aligned}
& \xi=M\left(1-\bar{v}_{\mathrm{p}} \rho_{0}\right) / s_{0} N_{\mathrm{A}} \\
& \xi=k T / D_{0}
\end{aligned}
$$

$k$, Boltzmann constant; $T$, temperature $(\mathrm{K}) ; \bar{v}_{\mathrm{p}}$, specific volume of polymer; $\rho_{0}$, density of the solvent; $N_{\mathrm{A}}$, Avogadro's number.

In this paper, we will rigorously estimate $A$ values from the molecular weight dependence of the frictional coefficient $\xi$ and compare them with those obtained in the pervious paper. ${ }^{1}$

\section{Theoretical Background}

According to the Kurata and Yamakawa (KY) theory, ${ }^{2} \xi$ of a flexible polymer chain in dilute solution is related to the draining parameter $X$ and $\left(\left\langle S^{2}\right\rangle_{0} / M\right)^{1 / 2}$ by eq 2 :

$$
\xi / \eta_{0}=3 \pi^{3 / 2}\left[X G_{0}(X)\right]\left(\left\langle S^{2}\right\rangle_{0} / M\right)^{1 / 2} M^{1 / 2} \alpha_{\mathrm{s}}^{m(X)}
$$




\section{K. KAMIDE and Y. MiYazAKI}

where $\eta_{0}=$ viscosity of the solvent, $G_{0}(X)$ and $m(X)=$ functions of $X$ given in the $\mathrm{KY}$ theory, $\alpha_{\mathrm{s}}=$ linear expansion factor $\left(=\left(\left\langle S^{2}\right\rangle \mid\left\langle S^{2}\right\rangle_{0}\right)^{1 / 2}\right.$, $\left\langle S^{2}\right\rangle^{1 / 2}=$ radius of gyration at perturbed state). Now, parameter $\boldsymbol{P}$, analogous to the Flory viscosity parameter $\Phi$, is defined as

$$
P=q_{\mathrm{w}, \mathrm{z}}^{\prime}\left(\xi / \eta_{0}\right) /\left(6^{1 / 2}\left\langle S^{2}\right\rangle_{\mathrm{z}}^{1 / 2}\right)
$$

where $q_{\mathrm{w}, \mathrm{z}}^{\prime}=$ polymolecularity correction factor (in this case, $D_{0}, M$, and $s_{0}$ are assumed to be the weight-average quantities; see Appendix).

Equation 2 can be rewritten with the aid of eq 3 in the form:

$$
\xi / \eta_{0}=6^{1 / 2} P\left(\left\langle S^{2}\right\rangle_{0} / M\right)^{1 / 2} M^{1 / 2} \alpha_{\mathrm{s}}
$$

with

$$
\begin{aligned}
& P=P_{0}(X) \alpha_{\mathrm{s}}^{-(1-m(X))} \\
& P_{0}(X)=\left(3 \pi^{3} / 2\right)^{1 / 2}\left[X G_{0}(X)\right]
\end{aligned}
$$

In the case when the draining effect is non-negligible (i.e., $X \lesssim 10$ ), $P$ is expected, from eq 5 and 6 , to be molecular weight dependent. This dependence can be semi-empirically expressed, to a first approximation, by eq 7 :

$$
P=K_{\mathrm{p}} M^{a_{\mathrm{p}}}
$$

Furthermore, if the non-Gaussian nature exists, the term $\left(\left\langle S^{2}\right\rangle_{0} / M\right)^{1 / 2}$ in eq 4 is not constant, but depends on the molecular weight. That is, the following equation

$$
\left(\left\langle S^{2}\right\rangle_{0} / M\right)\left(\equiv A^{2} / 6\right)=K_{0} M^{a_{2}}
$$

can be approximated.

$\alpha_{\mathrm{s}}$ in eq 4 is, according to the Fixman theory, ${ }^{3}$ given by:

$$
\text { where } \quad z=0.330 B A^{-3} M^{1 / 2}
$$

Substitution of eq $7-10$ in eq 4 gives

$$
\begin{aligned}
\xi / \eta_{0}= & 6^{1 / 2} K_{\mathrm{p}} K_{0}^{0.5} M^{0.5+0.5 a_{2}+a_{\mathrm{p}}} \\
& \times\left(1+0.0144 B K_{0}^{-1.5} M^{0.5-1.5 a_{2}}\right)
\end{aligned}
$$

Equation 11 holds for the case $a_{2} \neq 0$ and $a_{\mathrm{p}} \neq 0$. A graph of $\left(\xi / \eta_{\mathrm{o}}\right) / M_{\mathrm{W}}^{0.5+0.5 a_{2}+a_{\mathrm{p}}}$ as a function of $M_{\mathrm{W}}^{0.5-1.5 a_{2}}$ (Kamide-Miyazaki (KM) II plot) enables $6^{1 / 2} q_{\mathrm{w}, \mathrm{z}}^{\prime-1} K_{\mathrm{p}} K_{0}^{1 / 2}$ (and accordingly $K_{0}$ ) to be evaluated from the intercept at $M_{\mathrm{w}}^{0.5-1.5 a_{2}}=0$, where $M_{\mathrm{w}}$ is the weight-average molecular weight.
The $K_{0}$ thus estimated corresponds to $\left(\left\langle S^{2}\right\rangle_{0, z}\right)$ $\left.M_{\mathrm{w}}\right)\left(\equiv A_{\mathrm{z}, \mathrm{w}}\right)$ and was converted to the value corresponding to $\left(\left\langle S^{2}\right\rangle_{0, \mathrm{w}} / M_{\mathrm{w}}\right)$ ( $\left.\equiv A_{\mathrm{w}, \mathrm{w}}\right)$. We will call this method $2 \mathrm{~J}$ hereafter.

In the case $a_{2}=a_{\mathrm{p}}=0$, eq 11 reduces to

$\xi / \eta_{0}=P_{0}(\infty) \alpha_{\mathrm{s}}^{-0.348} A M_{-}^{0.5}\left(1+0.211 B A^{-3} M_{-}^{0.5} \cdots\right)$

where $\boldsymbol{P}_{0}(\infty)=\boldsymbol{P}_{0}$ value at $X=\infty$ and 5.2. ${ }^{2)}$ If $\alpha_{\mathrm{s}}^{-0.348} \simeq 1$, eq 12 can be written in the form

$\xi / \eta_{0}=P_{0}(\infty) A M^{0.5}\left(1+0.211 B A^{-3} M_{-}^{0.5} \cdots\right)$

which is almost the same equation as that derived by Cowie and Bywater. ${ }^{4} A$ can be determined from the plot of $\xi /\left(\eta_{0} M_{\mathrm{w}}^{0.5}\right)$ vs. $M_{\mathrm{w}}^{0.5}$ (CowieBywater (CB) plot) as the ordinate at $M_{\mathrm{w}}^{0.5}=0$ after the conversion of $A_{\mathrm{z}, \mathrm{w}}$ to $A_{\mathrm{w}, \mathrm{w}}$. This method will be referred to as method 2I for convenience.

Equation 11 is analogous to the viscosity equation:

$$
\begin{aligned}
{[\eta]=} & 6^{1.5} K_{\Phi} K_{0}^{1.5} M^{0.5+1.5 a_{2}+a_{\Phi}} \\
& \times\left(1+2(3 / 2 \pi)^{1.5} B A^{-3} M^{0.5}\right)
\end{aligned}
$$

which has been developed by us. ${ }^{1}$

\section{Application to Experimental data}

Literature data on cellulose, ${ }^{5}$ cellulose diacetate (CDA), ${ }^{6,7}$ cellulose tricarbanilate (CTC) ${ }^{8,9}$ ethylhydroxyethyl cellulose (EHEC), ${ }^{10}$ and amylose triacetate $(\mathrm{ATA})^{11}$ were analyzed extensively according to eq 10 and $12^{\prime}$ in order to determine $A$ or $K_{0}$.

Table I assembles $M_{\mathrm{w}} / M_{\mathrm{n}}\left(M_{\mathrm{n}}\right.$, the numberaverage molecular weight), $\bar{v}_{\mathrm{p}}, \rho_{0}$, and $\eta_{0}$ values for the above polymers in solvents. In the table are included $\varepsilon\left(\equiv \mathrm{d} \ln \alpha_{\mathrm{s}} / \mathrm{d} \ln M=a_{1} / 3\right)$ and $a_{2}$ values, determined in a previous paper. ${ }^{1} \quad q_{\mathrm{w}, \mathrm{z}}^{\prime}$ was calculated by eq $\mathrm{A} \cdot 14$ and $\mathrm{A} \cdot 15$ from $M_{\mathrm{w}} /$ $M_{\mathrm{n}}, \varepsilon$, and $a_{2}$ values.

The molecular weight dependence of Flory's parameter $P$ is demonstrated in Figure 1, in which the data can be well represented by eq 7 , with a positive $a_{\mathrm{p}}$. The values of $K_{\mathrm{p}}$ and $a_{\mathrm{p}}$ thus determined are also listed in the tenth and eleventh columns in Table I. Evidently, there is a close correlation, as expected, between $a_{\mathrm{p}}$ and $a_{\Phi}$ $(\equiv \mathrm{d} \ln \Phi / \mathrm{d} \ln M$ ) (correlation coefficient $r=0.71$ ), which acts as a rough measure of the draining 
Table I. Values of various parameters including $\bar{v}_{\mathrm{p}}, \rho_{0}, \eta_{0}, a_{2}, K_{\mathrm{p}}$, and $a_{\mathrm{p}}$ for some cellulose and amylose derivatives

\begin{tabular}{|c|c|c|c|c|c|c|c|c|c|c|}
\hline Polymer & Solvent & $M_{\mathrm{w}} / M_{\mathrm{n}}$ & $\varepsilon^{\mathrm{b}}$ & $\begin{array}{l}\text { Specific } \\
\text { volume of } \\
\text { polymer } \bar{v}_{\mathrm{p}} \\
\mathrm{cm}^{3} / \mathrm{g}\end{array}$ & $\begin{array}{l}\text { Density of } \\
\text { solvent } \rho_{0} \text {, } \\
\mathrm{g} / \mathrm{cm}^{3}\end{array}$ & $\begin{array}{c}\text { Viscosity } \\
\text { of solvent } \\
r_{j 0}, \\
\text { poise }^{\mathrm{d}}\end{array}$ & $\begin{array}{l}a_{2} \text { in } \\
\text { eq } 8^{\mathrm{e}}\end{array}$ & $s_{0}$ or $D_{0}$ & $\begin{array}{l}K_{\mathrm{p}} \text { in } \\
\text { eq } 7\end{array}$ & $\begin{array}{l}a_{\mathrm{p}} \text { in } \\
\text { eq } 7\end{array}$ \\
\hline Cellulose & Cadoxen $^{r}$ & $1.82-7.67$ & 0.07 & $-^{c}$ & - & - & -0.216 & $\left\{\begin{array}{l}s_{0} \\
D_{0}\end{array}\right.$ & $\begin{array}{l}2.10 \\
0.752\end{array}$ & $\begin{array}{l}0.067 \\
0.136\end{array}$ \\
\hline Cellulose diacetate & Acetone & $1.27-1.30$ & 0.04 & 0.700 & 0.788 & 0.00308 & -0.471 & $s_{0}$ & 0.122 & 0.311 \\
\hline Cellulose tricarbanilate & $\begin{array}{l}\text { Cyclo- } \\
\text { hexanone }\end{array}$ & $1.76-2.26$ & 0 & 0.513 & 0.947 & 0.022 & 0 & $s_{0}$ & 5.98 & 0.024 \\
\hline Ethylhydroxyethyl cellulose & Water & $3.08-3.23$ & 0.03 & 0.710 & 0.998 & 0.010 & -0.256 & $\left\{\begin{array}{l}s_{0} \\
D_{0}\end{array}\right.$ & $\begin{array}{l}0.0755 \\
0.0695\end{array}$ & $\begin{array}{l}0.328 \\
0.300\end{array}$ \\
\hline Sodium cellulose xanthate & $1-N \mathrm{NaOH}$ & $1.25^{\mathrm{a}}$ & 0 & 0.603 & 1.045 & 0.01104 & -0.240 & $s_{0}$ & 0.00558 & 0.504 \\
\hline Amyose tricarbanilate & Pyridine & $1.5^{\mathrm{a}}$ & 0.04 & 0.657 & 0.987 & 0.00987 & 0 & $s_{0}$ & 2.10 & 0.064 \\
\hline
\end{tabular}




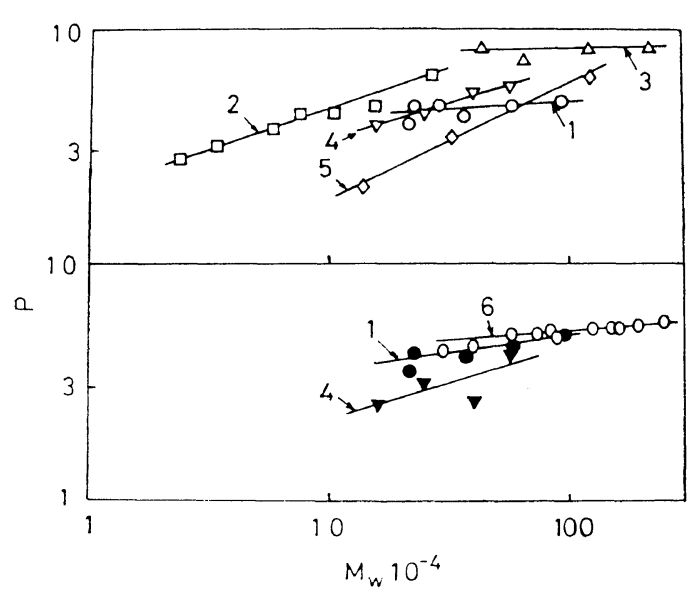

Figure 1. Molecular weight dependence of Flory's parameter $P$ : 1 , cellulose in cadoxen; 2 , cellulose diacetate in acetone; 3 , cellulose tricarbanilate in cyclohexanone; 4, ethylhydroxyethyl cellulose in water; 5 , sodium xanthate in $1-N \mathrm{NaOH} ; 6$, amylose tricarbanilate in pyridine; open mark, based on $s_{0}$ (eq 1 ); closed mark, based on $D_{0}$ (eq $1^{\prime}$ ).

effect. That is to say, the facts $a_{\mathrm{p}}>0$ and $a_{\Phi}>0$ mean that the draining effect is not ignorable for these polymers.

By use of eq 5 , we can estimate the $X$ value from $p$ and $\alpha_{\mathrm{s}}$. The latter can be evaluated from a penetration function $\psi$ in the manner described before. ${ }^{1}$ This method (method $1 \mathrm{G}$ ) is analogous to method $1 \mathrm{~A}$ in the previous paper, which is based on:

$$
\Phi=\Phi_{0}(X) \alpha_{\mathrm{s}}^{-(3-n(X))}
$$

where $n(X)$ is a function of $X$ defined by the $\mathrm{KY}$ theory. The result is summarized in Table II, in which the data obtained by method $1 \mathrm{~A}^{1}$ are also included. The average value of $X$ determined by method $1 \mathrm{G}$ agrees satisfactorily with that by method 1A, except for CTC and ATC. The experimental data for the former polymer seem less reliable, as will be discussed later. The conclusions drawn from Table II do not therefore contradict those from $a_{\Phi}$ and $a_{2}$.

Figure 2 shows the Cowie-Bywater plots. Least square straight lines in the figure were drawn through data points. The data points based on $s_{0}$ are denoted by open marks and those on $D_{0}$ by closed marks. The value of $A$, as estimated from the CB plot, is denoted by $A_{(2 \mathrm{I})}$

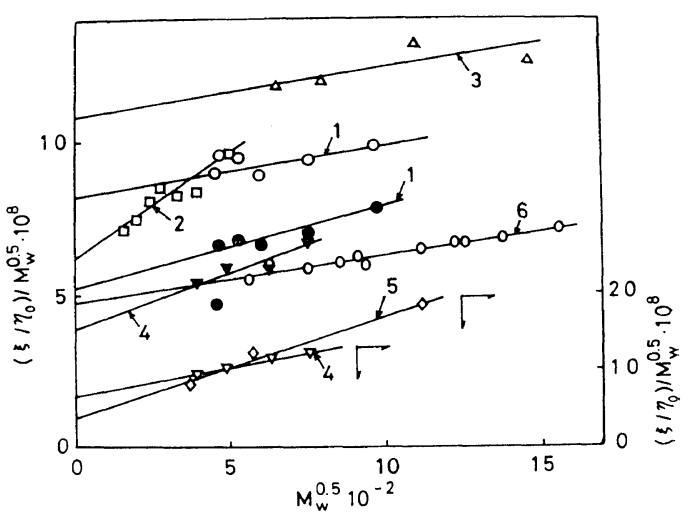

Figure 2. Plot of $\left(\xi / \eta_{0}\right) / M_{\mathrm{w}}^{0.5}$ against $M_{\mathrm{w}}^{0.5}$ (CowieBywater plot): numbers on curve have the same meaning as in Figure 1 and the ratio $\left(\xi / \eta_{0}\right)$ is expressed in $\mathrm{cm}$.

Table II. The draining parameter $X$ evaluated from Flory's parameters $P$ and $\Phi$

\begin{tabular}{|c|c|c|c|c|}
\hline \multirow{2}{*}{ Polymer } & \multirow{2}{*}{ Solvent } & \multirow{2}{*}{$s_{0}$ or $D_{0}$} & Method $1 G($ from $P$ ) & Method 1A (from $\Phi)^{1}$ \\
\hline & & & $X$ & $X$ \\
\hline Cellulose & Cadoxen & $s_{0}$ & $1.4 \sim 12(5.0)^{\mathrm{a}}$ & $2.2 \sim 9.2(5.4)^{a}$ \\
\hline Cellulose diacetate & Acetone & $\left\{\begin{array}{l}D_{0} \\
s_{0}\end{array}\right.$ & $\begin{array}{l}0.9 \sim 30(6.7)^{\mathrm{a}} \\
0.5 \sim * \mathrm{~b}(1.96)^{\mathrm{c}}\end{array}$ & $0.52 \sim 4.0(1.45)^{\mathrm{a}}$ \\
\hline Cellulose tricarbanilate & Cyclohexanone & $s_{0}$ & $*$ & $0.54 \sim 1.6(0.95)^{\mathrm{a}}$ \\
\hline Ethylhydroxyethyl cellulose & Water & $\left\{\begin{array}{l}s_{0} \\
D_{0}\end{array}\right.$ & $\begin{array}{l}0.55 \sim 10.0(3.7)^{\mathrm{a}} \\
0.38 \sim 1.5(0.73)^{\mathrm{a}}\end{array}$ & $0.48 \sim 4.3(2.0)^{\mathrm{a}}$ \\
\hline Sodium cellulose xanthate & $1-N \mathrm{NaOH}$ & $s_{0}$ & $0.28 \sim * \quad(0.49)^{\mathrm{c}}$ & $0.1 \sim 0.18(0.14)^{\mathrm{a}}$ \\
\hline Amylose tricarbanilate & Pyridine & $s_{0}$ & $2.1 \sim * \quad(13.2)^{\mathrm{c}}$ & $0.23 \sim 0.66(0.5)^{\mathrm{a}}$ \\
\hline
\end{tabular}

a Number in parenthesis means average.

b * denotes the case of $P>P_{0}(\infty)(\equiv 5.2)$.

c Number in parenthesis means average, which is obtained except for the case of $P_{0}>P_{0}(\infty)(\equiv 5.2)$. 


\section{Estimation of Unperturbed Dimensions of Cellulose}

Table III. Unperturbed chain dimensions $A$ and $K_{0}$ of cellulose and amylose derivatives

\begin{tabular}{|c|c|c|c|c|c|c|}
\hline Polymer & Solvent & $\begin{array}{l}\text { The most } \\
\text { reliable value } \\
A_{(\mathrm{m})}, 10^{8} \mathrm{~cm}^{\mathrm{a}}\end{array}$ & $s_{0}$ or $D_{0}$ & $\begin{array}{l}A_{(2 \mathrm{I})} \\
10^{8} \mathrm{~cm}\end{array}$ & $\begin{array}{c}K_{0}, 10^{16} \mathrm{~cm}^{2} \\
\text { by method } 2 \mathrm{~J}\end{array}$ & $\begin{array}{l}A_{(2 \mathrm{~J})},{ }^{\mathrm{c}} \\
10^{8} \mathrm{~cm}\end{array}$ \\
\hline Cellulose & Cadoxen & 1.71 & $\left\{\begin{array}{l}s_{0} \\
D_{0}\end{array}\right.$ & $\begin{array}{l}1.43 \\
1.18\end{array}$ & $\begin{array}{l}6.57 \\
5.71\end{array}$ & $\begin{array}{l}1.92 \\
2.04\end{array}$ \\
\hline $\begin{array}{l}\text { Cellulose } \\
\text { diacetate }\end{array}$ & Acetone & 1.84 & $s_{0}$ & 1.11 & 112.1 & 1.72 \\
\hline $\begin{array}{l}\text { Cellulose } \\
\text { tricarbanilate }\end{array}$ & $\begin{array}{l}\text { Cyclo- } \\
\text { hexanone }\end{array}$ & 1.35 & $s_{0}$ & $\begin{array}{l}1.96 \\
(1.98)^{\mathrm{b}}\end{array}$ & 0.318 & 1.48 \\
\hline $\begin{array}{l}\text { Ethylhydroxy- } \\
\text { ethyl cellulose }\end{array}$ & Water & 2.30 & $\left\{\begin{array}{l}s_{0} \\
D_{0}\end{array}\right.$ & $\begin{array}{l}1.08 \\
0.84\end{array}$ & $\begin{array}{l}11.92 \\
11.80\end{array}$ & $\begin{array}{l}2.16 \\
2.47\end{array}$ \\
\hline $\begin{array}{l}\text { Sodium cellulose } \\
\text { xanthate }\end{array}$ & $1-N \mathrm{NaOH}$ & 3.79 & $s_{0}$ & 0.73 & 33.51 & 3.63 \\
\hline Amylose carbanilate & Pyridine & 1.07 & $s_{0}$ & 0.88 & 0.154 & 1.02 \\
\hline
\end{tabular}

and shown in the fifth column of Table III. Table III also includes results obtained by Shanbhag for CTC in cyclohexanone. ${ }^{9}$ There is excellent agreement between Shanbhag's result and the present result. Except in the CTC-cyclohexanone system, $A_{(2 \mathrm{I})}$ is much smaller than the most reliable $A$ value $\left(A_{(\mathrm{m})}\right)$, as shown in Table III. $A_{(2 \mathrm{I})}$ is, on average, of the order of $50 \%$ of $A_{(\mathrm{m})}$.

In other words, method $2 \mathrm{I}$ underestimates $A$ considerably and is by no means applicable for cellulose, amylose, and their derivatives.

The Kamide-Miyazaki (II) plot is displayed in Figure 3. All points can be represented by straight lines over the entire range of molecular weight experimentally accesible. The values of $K_{0}$ together with the $A$ values at $M_{\mathrm{w}}=1 \cdot 10^{5}$ $\left(A_{(2 \mathrm{~J})}\right)$, are collected in the last two Columns in Table III. The results indicate that no significant difference exists between $A_{(2 \mathrm{~J})}$ and $A_{(\mathrm{m})}$ (correlation coefficient $r=0.97$ ) if experimental error is considered. It is immediately evident from Table III that the inapplicability of method 2I to cellulose, amylose, and their derivatives can be regarded as mainly due to the neglect of $a_{2}$ and $a_{\mathrm{p}}$. Comparison of eq 11 and $12^{\prime}$ reveals that $A_{(2 \mathrm{I})}$ may coincide with $A_{(2 \mathrm{~J})}$, and accordingly with $A_{(\mathrm{m})}$, at $a_{\mathrm{p}}+0.5 a_{2}=0$. This prediction is experimentally confirmed for cellulose and amylose derivatives, as shown in Figure 4, in which the ratio $A_{(2 \mathrm{I})} / A_{(2 \mathrm{~J})}$ decreases gradually with an increase in $a_{\mathrm{p}}+0.5 a_{2}$. For the system of cellulose tricarbanilate in cyclohexanone, the

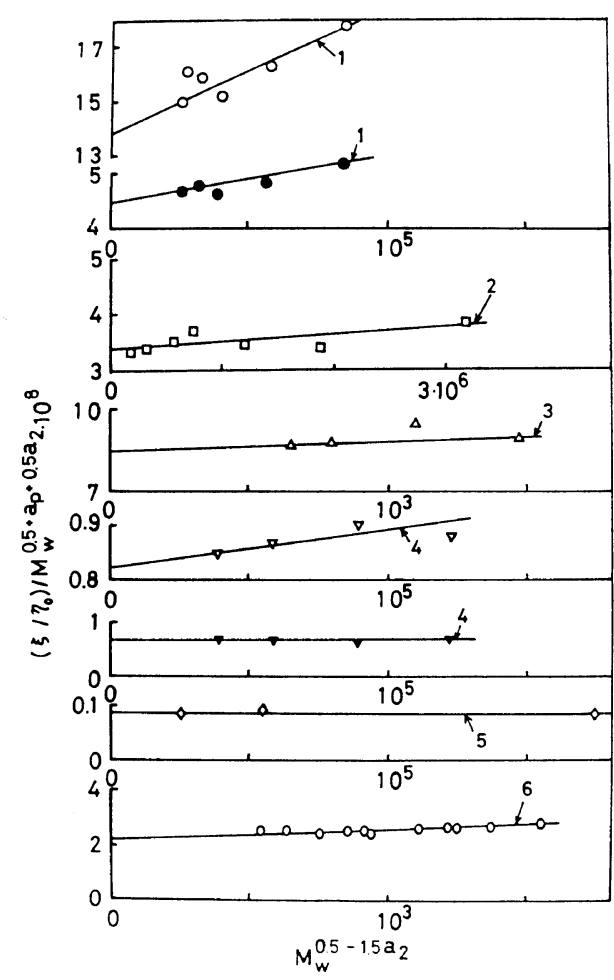

Figure 3. Plot of $\left(\xi / r_{0}\right) / M_{\mathrm{w}}^{0.5+0.5 a_{2}+a_{\mathrm{p}}}$ against $M_{\mathrm{w}}^{05-1.5 a_{2}}$ (Kamide-Miyazaki (II) plot). Numbers on curve have the same meaning as in Figure 1 and the ratio $\xi / \eta_{0}$ is expressed in $\mathrm{cm}$. 


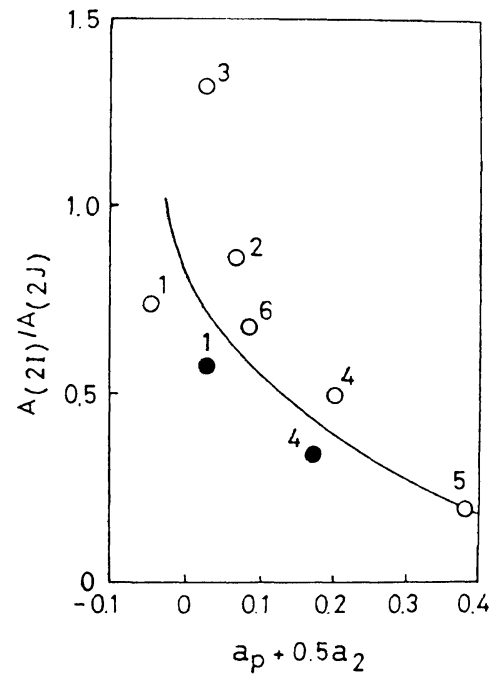

Figure 4. Correlationships between the ratio $A_{(2 \mathrm{I})} /$ $A_{(2 \mathrm{~J})}$ and $a_{\mathrm{p}}+0.5 a_{2}$. Numbers on curve have the same meaning as in Figure 1.

large value of $A_{(2 \mathrm{I})} / A_{(2 \mathrm{~J})}$ cannot be interpreted in terms of $a_{\mathrm{p}}+0.5 a_{2}(=0.024)$. The $P$ values calculated for this system $(7.36 \sim 8.49)$ are much larger than the theoretical maximum value $P_{0}(\infty)$ (=5.2) (see Figure 1), suggesting that the experimental results are seriously questionable and that the application of method 2I to the above system leads unavoidably to an overestimation of the $A$ value.

Therefore, we come to the conclusion that the unperturbed chain dimensions can be adequately estimated from the molecular weight dependence of $s_{0}$ and $D_{0}$ according to eq 11 , where both $a_{2}$ and $a_{\mathrm{p}}$ are satisfactorily taken into account.

The slope of Kamide-Miyazaki's (II) plot and of Cowie-Bywater's plot affords us a long-range interaction parameter $B$. Then the second virial coefficient $A_{2}$ can be readily calculated from $A$ and $B$ thus estimated by the plots and from the experimental weight-average radius of gyration $\left\langle S^{2}\right\rangle_{\mathrm{W}}{ }^{1 / 2}$ by using the relation:

$$
A_{2}=\left(N_{\mathrm{A}} / 2\right) B h_{0}(z)
$$

Here $h_{0}(z)$ is a function of $z$, for which various theories have been presented. In this study, the Kurata - Fukatsu - Yamakawa - Sotobayashi ${ }^{12}$ theory was employed. But the results do not change significantly even if other solution theories

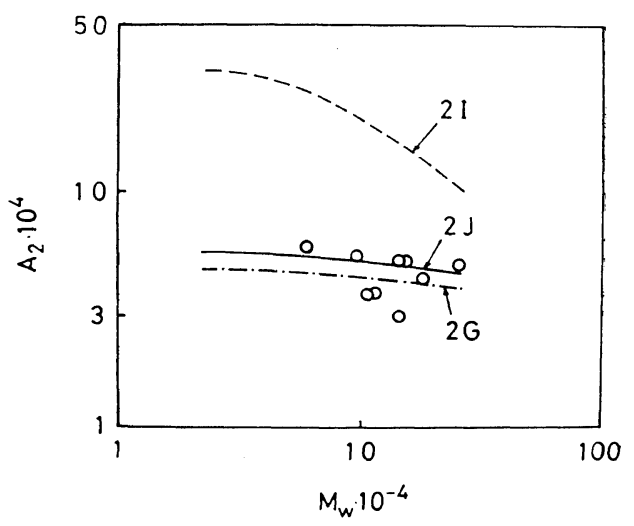

Figure 5. Molecular weight dependence of the second virial coefficient $A_{2}$ for cellulose diacetate in acetone: $\bigcirc$, experimental data point $^{\theta}$ by light scattering; chain, broken, and full lines; $A_{2}$, values calculated from $A, B$ (by methods 2G, 2I, and 2J) and the experimental weight-average radius of gyration $\left\langle S^{2}\right\rangle_{\mathrm{w}}{ }^{1 / 2}$.

are used, because for cellulose and amylose derivatives $z$ is in vicinity of zero. Figure 5 illustrates the plots of $A_{2}$ against $M_{\mathrm{w}}$ for cellulose diacetate in acetone. In this figure, the open circles represent experimental values ${ }^{6}$ and the broken and full lines represent the $A_{2}$ values calculated from $A$ and $B$, which are evaluated by methods $2 \mathrm{I}$ and $2 \mathrm{~J}$, respectively. The calculated line based on method $2 \mathrm{G}$ (eq 13) is also included. Obviously, method $2 \mathrm{~J}$ as well as method $2 \mathrm{G}$ can follow the experimental values of $A_{2}$ quite reasonably.

To summarize, the concept of $a_{2}$ and $a_{\mathrm{p}}$ (or $\left.a_{\Phi}\right)$ is very successful in explaining the dilute solution properties of cellulose, amylose, and their derivatives in a consistent manner and the best and most widely used methods for estimating $A$ from hydrodynamic data are methods $2 \mathrm{G}$ and $2 \mathrm{~J}$, both developed by us.

\section{APPENDIX}

Polydispersity Correction Factor $q_{\mathrm{w}, \mathrm{z}}^{\prime}$ in eq 3

We define $\xi_{\mathrm{w}, \mathrm{w}(\mathrm{s})}$ and $\xi_{\mathrm{w}(\mathrm{D})}$ by eq A.1 and A.1', respectively:

$$
\begin{aligned}
& \xi_{\mathrm{w}, \mathrm{w}(\mathrm{s})}=M_{\mathrm{w}}\left(1-\bar{v}_{\mathrm{p}} \rho_{0}\right) / s_{0, \mathrm{w}} N_{\mathrm{A}} \\
& \xi_{\mathrm{w}(\mathrm{D})}=k T / D_{0, \mathrm{w}}
\end{aligned}
$$


Estimation of Unperturbed Dimensions of Cellulose

where $s_{0, \mathrm{w}}$ and $D_{0, \mathrm{w}}$ are the weight-average sedimentation and diffusion coefficients at infinite dilution.

The following relations exist between $\xi_{\mathrm{w}, \mathrm{w}(\mathrm{s})}$ or $\hat{\xi}_{\mathrm{w},(\mathrm{D})}$ and the weight-average friction coefficient $\xi_{\mathrm{w}}$ :

$$
\xi_{\mathrm{w}}=q_{\mathrm{s}} \xi_{\mathrm{w}, \mathrm{w}(\mathrm{s})}
$$

or

$$
\xi_{\mathrm{w}}=q_{\mathrm{D}} \xi_{\mathrm{w}(\mathrm{D})}
$$

with

$$
q_{\mathrm{s}}=\left\langle M / s_{0}\right\rangle_{\mathrm{w}} s_{0, \mathrm{w}} / M_{\mathrm{w}}
$$

$$
q_{\mathrm{D}}=\left\langle 1 / D_{0}\right\rangle_{\mathrm{w}} D_{0, \mathrm{w}}
$$

the suffix $w$ means weight-average.

$\xi_{\mathrm{w}}$ is related to $\left\langle S^{2}\right\rangle_{\mathrm{z}}{ }^{1 / 2}$ by the relation:

$$
\xi_{\mathrm{w}}=q_{\mathrm{p}} P \eta_{0} 6^{1 / 2}\left\langle S^{2}\right\rangle_{\mathrm{z}}^{1 / 2}
$$

where

$$
q_{\mathrm{p}}=\left\langle\left\langle S^{2}\right\rangle^{1 / 2}\right\rangle_{\mathrm{w}} /\left\langle S^{2}\right\rangle_{\mathrm{z}}^{1 / 2}
$$

$\left\langle S^{2}\right\rangle^{1 / 2}$ is the square root of the mean-square radius of gyration averaged over all possible conformations of the chains.

Therefore, $q_{\mathrm{w}, \mathrm{z}}^{\prime}$ in eq 3 can be expressed by the ratio $q_{\mathrm{s}} / q_{\mathrm{p}}$ or $q_{\mathrm{D}} / q_{\mathrm{p}}$ :

$$
\begin{gathered}
q_{\mathrm{w}, \mathrm{z}(\mathrm{s})}^{\prime}=q_{\mathrm{s}} / q_{\mathrm{p}}=\frac{\left[\int\left\langle S^{2}\right\rangle M g(M) \mathrm{d} M\right]^{1 / 2} \int s_{0} g(M) \mathrm{d} M \cdot \int \frac{M}{s_{0}} g(M) \mathrm{d} M}{\int\left\langle S^{2}\right\rangle^{1 / 2} g(M) \mathrm{d} M \cdot\left[\int M g(M) \mathrm{d} M\right]^{3 / 2}} \\
q_{\mathrm{w}, \mathrm{z}(\mathrm{D})}^{\prime}=q_{\mathrm{D}} / q_{\mathrm{p}}=\frac{\left[\int\left\langle S^{2}\right\rangle M g(M) \mathrm{d} M\right]^{1 / 2} \int \frac{g(M)}{D_{0}} \mathrm{~d} M \int D_{0} g(M) \mathrm{d} M}{\int\left\langle S^{2}\right\rangle^{1 / 2} g(M) \mathrm{d} M \cdot\left[\int M g(M) \mathrm{d} M\right]^{1 / 2}}
\end{gathered}
$$

where $g(M)=$ normalized differential weight distribution. It should be noticed that $q_{\mathrm{w}, \mathrm{z}(\mathrm{s})}^{\prime} \neq q_{\mathrm{w}, \mathrm{z}(\mathrm{D})}^{\prime}$.

Equations A.6 and A.7 can be rewritten as

$$
\begin{aligned}
& q_{\mathrm{w}, \mathrm{z}(\mathrm{s})}^{\prime}= {\left[\int M^{2+a_{2}+2 \varepsilon} g(M) \mathrm{d} M\right]^{1 / 2} \int M^{a_{\mathrm{s}}} g(M) \mathrm{d} M \int M^{1-a_{\mathrm{s}}} g(M) \mathrm{d} M } \\
& q_{\mathrm{w}, \mathrm{z}(\mathrm{D})}^{\prime}=\frac{\left[\int M^{0.5+0.5 a_{2}+\varepsilon} g(M) \mathrm{d} M\left[\int M g(M) \mathrm{d} M\right]^{3 / 2}\right.}{\left.\int M^{2+a_{2}+2 \varepsilon} g(M)\right]^{1 / 2}\left[M^{-a_{\mathrm{d}}} g(M) \mathrm{d} M \int M^{a_{\mathrm{d}}} g(M) \mathrm{d} M\right.} \\
& \int M^{0.5+0.5 a_{2}+\varepsilon} g(M) \mathrm{d} M\left[\int M g(M) \mathrm{d} M\right]^{1 / 2}
\end{aligned}
$$

where

$$
\begin{gathered}
\varepsilon=\mathrm{d} \ln \alpha_{\mathrm{s}} / \mathrm{d} \ln M=a_{1} / 3 \\
a_{\mathrm{S}}=\mathrm{d} \ln s_{0} / \mathrm{d} \ln M
\end{gathered}
$$

according to the Kurata-Yamakawa theory, $a_{\mathrm{s}}$ and $a_{\mathrm{d}}$ are given by eq A.12 and A.13:

$$
\begin{gathered}
a_{\mathrm{s}}=0.5-\mu(X)+\left(1-m(X) \varepsilon-0.5 a_{2}-\varepsilon\right. \\
a_{\mathrm{d}}=-\mu(X)-m(X) \varepsilon-0.5 a_{2}-0.5=a_{\mathrm{s}}-1.0
\end{gathered}
$$

$$
q_{\mathrm{w}, \mathrm{z}(\mathrm{s})}^{\prime}=
$$

$$
\frac{\left[\Gamma\left(3+h+a_{2}+2 \varepsilon\right)\right]^{1 / 2} \Gamma\left(1+h+a_{\mathrm{s}}\right) \Gamma\left(2+h-a_{\mathrm{s}}\right)}{\Gamma\left(1.5+h+0.5 a_{2}+\varepsilon\right)[\Gamma(2+h)]^{3 / 2}}
$$

$$
q_{\mathrm{w}, \mathrm{z}(\mathrm{D})}^{\prime}=
$$

$$
\frac{\left[\Gamma\left(3+h+a_{2}+2 \varepsilon\right]^{1 / 2} \Gamma\left(1+h+a_{\mathrm{d}}\right) \Gamma\left(1+h-a_{\mathrm{d}}\right)\right.}{\Gamma\left(1.5+h+0.5 a_{2}+\varepsilon\right)[\Gamma(2+h)]^{1 / 2} \Gamma(1+h)}
$$

When $g(M)$ is expressed by the Schulz-Zimm distribution, eq A.8 and A.9 can be readily converted into

$$
h^{-1}=\left(M_{\mathrm{w}} / M_{\mathrm{n}}\right)-1
$$




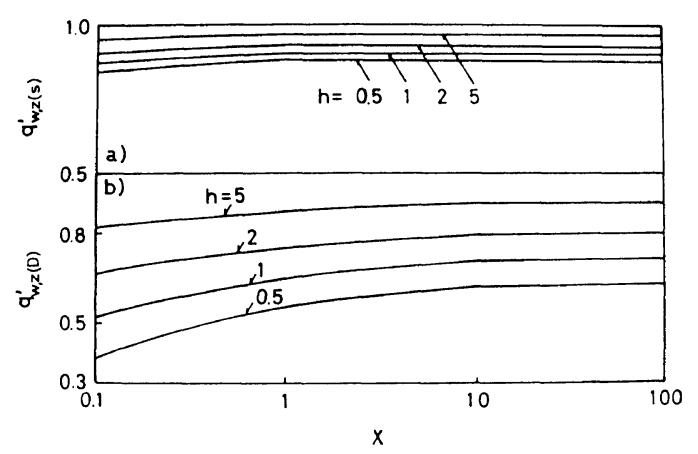

Figure 6. Plots of correction factors $q_{\mathrm{w}, \mathrm{z}(\mathrm{s})}^{\prime}$ and $q_{\mathrm{w}, \mathrm{z}(\mathrm{D})}^{\prime}$ against the draining parameter $X$ for the polymers with different polymolecularity $h ; a_{2}=$ -0.20 and $\varepsilon=0.03$.

and $\Gamma(X)=$ gamma function of $X$

By putting $X=\infty, a_{2}=0$, and $(1-m(X)) \varepsilon \simeq 0$, eq A.14 and A.15 reduces to

$$
\begin{aligned}
q_{\mathrm{w}, \mathrm{z}(\mathrm{s})}^{\prime} & =\frac{[\Gamma(3+h+2 \varepsilon)]^{1 / 2} \Gamma(1.5+h-\varepsilon)}{[\Gamma(2+h)]^{3 / 2}} \\
q_{\mathrm{w}, \mathrm{z}(\mathrm{D})}^{\prime} & =\frac{[\Gamma(3+h+2 \varepsilon)]^{1 / 2} \Gamma(0.5+h-\varepsilon)}{\left[(1+h)[\Gamma(2+h)]^{1 / 2}\right.}
\end{aligned}
$$

Equation A.17 has been already derived by Gouinlock, Flory, and Scheraga. ${ }^{13}$ In other words, eq A.14 is a straightforward generalization of eq A.17.
The effect of the polymolecularity of the polymers and the draining effect on the correction factors $q_{\mathrm{w}, \mathrm{z}(\mathrm{s})}^{\prime}$ and $q_{\mathrm{w}, \mathrm{z}(\mathrm{D})}^{\prime}$ is illustrated in Figure 6 , where $a_{2}=-0.20$ and $\varepsilon=0.03$ are assumed.

\section{REFERENCES}

1. K. Kamide and Y. Miyazaki, Polym. J. 10, 409 (1978).

2. M. Kurata and H. Yamakawa, J. Chem. Phys., 29, 311 (1958).

3. M. Fixman, J. Chem. Phys., 23, 1656 (1955).

4. J. M. G. Cowie and S. Bywater, Polymer, 6, 197 (1965).

5. D. Henley, Ark. Kemi, 18, 327 (1961).

6. K. Kamide, T. Terakawa, and Y. Miyazaki, unpublished result.

7. K. Kamide, H. Komatsu, T. Terakawa, and S. Ishida, Collection of Preprints, presented at 1977 Joint Niigata Meeting of the Chemical Society of Japan and the Society of Polymer Science Japan, 1977, p 19.

8. V. P. Shanbhag, Ark. Kemi, 29, 33 (1968).

9. V. P. Shanbhag, Ark. Kemi, 29, 139 (1968).

10. R. S. J. Manley, Ark. Kemi, 9, 519 (1956).

11. W. Banks, C. T. Greenwood, and J. Sloss, Eur. Polym. J., 7, 263 (1971).

12. M. Kurata, M. Fukatsu, H. Sotobayashi, and H. Yamakawa, J. Chem. Phys., 41, 139 (1964).

13. E. V. Gouinlock Jr., P. J. Flory, and H. A. Scheraga, J. Polym. Sci., 14, 383 (1955). 